\title{
Developing Trauma-Informed Care Champions: A Six-Month Learning Collaborative Training Model
}

\author{
Samantha P. Koury \\ Susan A. Green
}

\begin{abstract}
This paper describes a six-month learning collaborative for service providers seeking to implement trauma-informed care (TIC) into their agencies. Although the professional literature on trauma-informed care has grown substantially over the past 10 years, little research has focused on how to effectively train agencies in creating a traumainformed culture shift. Participants were trained as "TIC champions" to help facilitate the creation of trauma-informed approaches in their agencies. Through a parallel process, they learned the skills for planning and implementing a trauma-informed approach in their agency. At the completion of the training, trainers observed champions becoming more confident in their ability to assist their agencies in creating a trauma-informed culture shift. Though quantitative studies evaluating the learning collaborative are needed, initial findings suggest the collaborative approach is an effective means of guiding champions through the process of becoming trauma-informed.
\end{abstract}

Keywords: Trauma-informed care; agency change; training

Research indicates that trauma/adversity is a pervasive public health concern (Hornor, 2015; Roberts, Huang, Crusto \& Kaufman, 2014; Substance Abuse and Mental Health Services Administration [SAMHSA], 2014b). The Adverse Childhood Experiences (ACE) study found that more than one-half of the study participants experienced at least one adverse event such as physical or sexual abuse during their childhood (Felitti et al., 1998). Adversity does not necessarily equate to trauma; however, people who experience adverse events may perceive the events as traumatic. Kilpatrick et al. (2013) found $89.7 \%$ of the 2,953 adults in their study reported having been exposed to at least one traumatic event as defined by the DSM-5's Criterion A (American Psychiatric Association [APA], 2013). Due to the pervasiveness of trauma, multiple service sectors - beyond behavioral health interact daily with individuals who have a trauma history (SAMHSA, 2014b). Although it is not the role of all sectors to treat trauma directly by offering trauma-specific services, sectors that work with trauma survivors have the potential to re-traumatize, or replicate the dynamics of an individual's trauma, through trauma-insensitive practices and proceduresthus worsening service outcomes.

\section{Trauma-Informed Care}

Trauma-informed care (TIC) is an organizational approach that strives to prevent retraumatization while promoting healing. The TIC service provider approaches each client with the assumption the individual may have experienced trauma (Wolf, Green, Nochajski, Mendel \& Kusmaul, 2014). Service organizations themselves are starting to shift toward becoming trauma-informed systems of care in order to better address the needs of

\footnotetext{
Samantha P. Koury, LMSW is Project Manager, Institute on Trauma and Trauma-Informed Care, School of Social Work, University at Buffalo, State University of New York, Buffalo, NY 14260-1050. Susan A. Green is Clinical Associate Professor, School of Social Work, University at Buffalo, State University of New York, Buffalo, NY 14260-1050. 
individuals with trauma histories (Bassuk, Unick, Paquette, \& Richard, 2017; Wolf et al., 2014).

Professionals' interactions with service recipients, as well as agency policies and procedures that are trauma-informed, reflect the paradigm shift from, "What is wrong with you?" to "What has happened to you," and are anchored in the guiding values of safety, trustworthiness, choice, collaboration and empowerment (Harris \& Fallot, 2001). Becoming trauma-informed involves culture change within organizations, and incorporates all levels of staff, which often results in flattening the agency hierarchy (Bloom, 2013).

Organizational culture refers to the shared, imbedded assumptions of staff members (Schein, 2010). Bloom (2006) argues that the majority of agency cultures are based on a medical model of treatment, and that this culture needs to shift away from a hierarchical power dynamic towards a more flattened, collaborative environment in order to be more trauma-informed. It is ultimately the function of leadership within an organization to identify the agency's culture and transform it when it is no longer responsive to the environment (Schein, 2010). Leaders that champion the change process by being supportive and providing direction for change are critical (Shultz, 2014). The development of "champions" is thus necessary for sustainability, as they continuously identify both the key factors contributing to sustaining organizational change and factors acting as barriers in order to address them (Buchanan et al., 2005). Buono and Subbiah (2014) state that organizational change capacity is partially reliant on organizational members that have knowledge of change approaches and are willing to manage change-further contextualizing the importance and role of champions in the change process. These organizational members have the potential to mentor other staff, assess and monitor implementation goals, and assist in oversight of the overall change process, which helps build the infrastructure for sustainability (Buono \& Subbjah, 2014). The development of internal champions is thus critical for trauma-informed organizational change.

The existing literature on champions within trauma-informed organizations indicates they are the individuals who have knowledge about trauma and its impacts; prioritize sensitivity in all aspects of organizational functioning; and provide expertise to promote and support changes to policies, practices, and staff development (Harris \& Fallot, 2001; Jennings, 2009). While all staff members should have foundation knowledge around trauma and TIC in a trauma-informed organization, TIC champions think "trauma first" and highlight potential concerns to other professionals in the service delivery system (Harris \& Fallot, 2001). Frameworks for TIC also delineate that champions of the approach are often necessary to initiate and sustain organizational change (SAMHSA, 2014a; Harris $\&$ Fallot, 2001). Champions are able to facilitate change and function as part of the infrastructure for overall sustainability by taking on the roles of educator, mentor, coach, consultant, and/or advocate.

\section{Training}

While there is a gap in the literature describing models of TIC training, there is a growing body of literature around what content should be covered and the structure to use for staff trainings to effectively create trauma-informed culture change (Harris \& Fallot, 
2001; Jennings, 2009; SAMHSA, 2014a, 2014b). Fallot and Harris (2009) propose an initial kickoff training that covers the key components of trauma-informed cultures, the importance of applying TIC to staff as well as clients, and the degree of importance trauma holds with the agency looking to be trained. Short-term and long-term follow-ups to the initial training are recommended to deepen staff understanding of trauma, how to implement TIC with clients, and how TIC applies to them as staff (Harris \& Fallot, 2001). Similarly, SAMHSA (2014b) advises agencies to focus on the impacts of trauma and how agency practices can unintentionally replicate the dynamics of an individual's trauma history and thus be re-traumatizing. Training should also deliberately focus on ways the agency can prevent re-traumatization and how to identify, prevent, and address secondary traumatization and vicarious trauma.

Trauma and TIC training content needs to be framed in overarching historical and cultural considerations (Jennings, 2009; SAMHSA, 2014b). In light of TIC's emphasis on healing and growth, and the growing literature around the human capacity to bounce back and even flourish after experiencing adversity or a traumatic event, it is important for staff to learn how to promote resilience and posttraumatic growth (American Psychological Assocation, 2016; Calvo, Ukeje, Abraham \& Libman, 2016; Tedeschi \& Calhoun, 2004).

There is some evidence that longitudinal, multifaceted, and interactive education strategies may be more effective for long-lasting changes in skills, attitudes and practice approaches than single-session workshops or trainings (Hoge et al., 2007; Pearce et al., 2012). TIC implementation involves a culture shift that needs to be reflected in all aspects of agency functioning (Harris \& Fallot, 2001). Such a change arguably can take a few years to achieve. Not surprisingly, SAMHSA (2014b) advises agency administrators to invest in TIC trainings that are longitudinal, emphasize interactive and experiential learning activities, and are geared toward training a core group of staff who can then train other staff. Further, in a review of TIC in in-patient settings, Muskett (2014) concurs that ongoing trauma-informed education and skill development, mentoring, and regular debriefing are key components of successful TIC implementation. Hall and colleagues (2016) explored the effectiveness of single day TIC training for emergency department nurses and found that while the nurses' understanding of TIC increased, the participants were not confident in their ability to implement trauma-informed approaches due to various complexities of their work environment. Without an organizational culture shift impacting policies, procedures, and day-to-day interactions, TIC is not sustainable. Based on the findings of Hall et al. (2016), the evidence that longitudinal trainings may be more effective for creating longer lasting changes, and the training recommendations provided by Harris and Fallot (2001) and SAMHSA (2014b), an effective training model for TIC implementation needs to be staged and offered over time.

Because of the difficulties in creating and sustaining agency cultural change to a TIC approach, and the limited body of literature on TIC training, the purpose of this paper is to fill the gap in the literature by describing the use of a six-month learning collaborative model for training TIC champions. 


\section{The Learning Collaborative}

An interactive learning collaborative model was created in order to train "TIC champions" over a six-month period. The collaborative was developed based on the need to create sustainable trauma-informed organizational change and the literature supporting the use of longitudinal TIC training. Participants in the collaborative were trained on how to create trauma-informed agencies based on the components of effective TIC training described earlier. By expanding a train-the-trainer approach, the learning collaborative not only provided champions with content and resources, but also promoted a parallel process through the trainers' modeling of skills, activities, and discussions - putting the champions in the position to bring the information and resources back to their own agencies for planning and implementation.

\section{Selection of Champions}

The champion team was created as part of a state-wide initiative to build agency capacity for TIC within the adolescent substance use system of care. Applications were sent to multiple addiction programs across New York State and included information about the learning collaborative, expectations for being a TIC champion, and the requirements for participation. Champions were expected to attend and participate in all components of the learning collaborative, have the ability to implement changes in their agencies, and have the ability to train and coach other staff.

Harris and Fallot (2001) stress the importance of administrative support for trauma-informed organizational change. Thus, we requested applications to be filled out by both the tentative champion and their supervisor/administrator, as well as required a signed attestation of commitment to TIC capacity building by the agency's executive director. Table 1 below depicts the questions asked in the application.

Table 1.Questions on TIC Champion Application

Questions for future TIC champions

\begin{tabular}{l|l}
\hline $\begin{array}{l}\text { What is your "best hope" of being a TIC } \\
\text { champion? }\end{array}$ & $\begin{array}{l}\text { Describe the future TIC champion's ability to } \\
\text { implement changes in agency policy and } \\
\text { practice to promote TIC. } \\
\text { Describe the steps your agency has already } \\
\text { taken to train staff or implement a TIC } \\
\text { approach to service delivery. }\end{array}$ \\
$\begin{array}{l}\text { What are you already doing that tells you, "I be an effective TIC champion"? } \\
\text { will }\end{array}$ & \\
$\begin{array}{l}\text { How do you see yourself assisting in the } \\
\text { implementation of TIC at your workplace? }\end{array}$ & \\
$\begin{array}{l}\text { Describe your experience/ability in being a } \\
\text { leader, trainer and/or mentoring others. }\end{array}$ & \\
$\begin{array}{l}\text { Describe your ability to implement changes } \\
\text { in agency policy and practice to promote } \\
\text { TIC. }\end{array}$ & \\
\hline
\end{tabular}


Applications were reviewed separately by two individuals who ranked each application based on the applicant's ability to implement change, train other staff, and the changes their agency has already taken toward becoming more trauma-informed. Thirty champions from across New York State were chosen based on mutual agreement of the reviewers. The majority of the team was comprised of individuals in middle-management roles such as clinical supervisors and program directors/coordinators, with a smaller portion represented by direct care staff.

Once chosen, the champions were e-mailed a congratulatory letter, details about the first in-person training and directions for creating an account to access the required online continuing education course. They were also sent a link to an online, 10 question TIC knowledge and attitudes pre-test created by the authors and their colleagues via Survey Monkey to get a baseline assessment before any training began. Individuals who were not chosen were also sent letters thanking them for their interest.

\section{Foundational Trauma Knowledge}

As stated earlier, all agency staff working in a trauma-informed organization have foundational knowledge about trauma and TIC (Harris \& Fallot, 2001; SAMHSA, 2014b). Before attending the initial training, champions were asked to complete a one and one-half hour online course titled "Trauma 101: An Overview of Psychological Trauma," provided through the University at Buffalo's School of Social Work Continuing Education Program to ensure they had a basic understanding of trauma, re-traumatization, the ACE Study, and an overview of Harris and Fallot's (2001) five values of TIC. To strengthen their knowledge around trauma and TIC within the addictions field, champions were also asked to read the first chapter of Greenwald's (2014) Child Trauma Handbook: A Guide for Helping Trauma-Exposed Children and Adolescents and an article titled "TraumaInformed Care and Addiction Recovery: An Interview with Nancy J. Smyth" (Steiker, 2015).

\section{Initial Training}

All champions were required to attend a seven-hour, in-person training during the first month of the collaborative. Champions received folders with various handouts to reference during the day, a copy of the PowerPoint slides, and a document detailing the schedule for assignments, consultation options, and evaluations. After the champions introduced themselves, the trainers asked what needed to happen during the training to make it worthwhile. These "best hopes" were recorded on an easel in order to reference at the end of the day.

Using the work of Steiker (2015), one of the trainers anchored the group around what it means to be a champion by talking about his own experience in organizational change. This discussion highlighted five pieces of advice to consider as a champion over the course of the collaborative: personally commit to the role of a champion, involve key stakeholders in their agency in the process, remember the importance of senior leadership support, ensure that an organizational assessment is conducted early in the process, and to be relentless in advocating for trauma-informed practices. 
The training then moved onto a brief review of trauma by taking a deliberate look at what the champions were already noticing in their work around trauma and addiction, and having an in-depth discussion around re-traumatization. The morning ended with the differentiation between the three levels of trauma practice: trauma-informed, the overarching umbrella consisting of the guiding principles of TIC; trauma-sensitive, considering the physical environment and day-to-day interactions for the potential of retraumatization, as well as screening and assessing for trauma; and trauma-specific, providing evidence-based trauma treatments such as Trauma-Focused Cognitive Behavioral Therapy (TF-CBT) and Eye Movement Desensitization and Reprocessing (EMDR). Table 2 below depicts the content covered and its objective.

Table 2. Morning Training Content and Objectives

\begin{tabular}{|c|c|}
\hline $\begin{array}{r}\text { Topic/Discussion } \\
\end{array}$ & Objective \\
\hline $\begin{array}{l}\text { Understanding trauma (lecture) } \\
\text { - Impacts on the body } \\
\text { - Historical trauma } \\
\text { - Impacts on world view }\end{array}$ & - Explain how trauma may affect individuals \\
\hline $\begin{array}{l}\text { Addiction and its impact (discussion) } \\
\text { - What are you noticing about the individuals } \\
\text { you treat? } \\
\text { - What do you notice about your staff and how } \\
\text { they "interface" with client's addiction? } \\
\text { "interface" with the organization/system in } \\
\text { regards to the treatment of addiction? }\end{array}$ & $\begin{array}{l}\text { - Identify ways in which trauma impacts } \\
\text { addiction } \\
\text { - Identify current staff and system } \\
\text { interactions and procedures }\end{array}$ \\
\hline $\begin{array}{l}\text { Re-traumatization (lecture) } \\
\text { - What is it? } \\
\text { - The story of Anna Jennings (Jennings, 1994) } \\
\text { - How common mental health practices mirror } \\
\text { the dynamics of a trauma experience } \\
\text { - Impact of re-traumatization on clients } \\
\text { - Impact of re-traumatization on staff }\end{array}$ & $\begin{array}{l}\text { - Increase awareness of potential re- } \\
\text { traumatization through interactions, } \\
\text { procedures and policies } \\
\text { - Recognize the impact of re-traumatization } \\
\text { on clients and staff }\end{array}$ \\
\hline $\begin{array}{l}\text { Three levels of trauma practice (lecture) } \\
\text { - Trauma-informed } \\
\text { - Trauma-sensitive } \\
\text { - Trauma-specific }\end{array}$ & $\begin{array}{l}\text { - Be able to articulate the difference between } \\
\text { the three levels of trauma practice } \\
\text { - Identify the levels of practice that make } \\
\text { sense for their organization }\end{array}$ \\
\hline
\end{tabular}

The afternoon portion of the training focused on organizational change. The champions were first divided into five groups of six and given a large piece of paper with one of the five values listed on it. The group members were asked to come up with at least five things their programs are already doing that demonstrate organizational change for both clients and staff. The three trainers listened and asked prompting questions as necessary. Each group reported what it discussed while other groups were invited to share additional thoughts. 
After reconvening as a big group, the champions learned about the steps for creating trauma-informed culture change in human service programs, completed the "TraumaInformed Care in Youth Serving Settings: Organizational Self Assessment" (Traumatic Stress Institute of Klingberg Family Centers, n.d.) as an activity to demonstrate the various components of trauma-informed organizational change, and were given an overview of the ten implementation domains proposed by SAMHSA (2014a). Table 3 provides an overview of the afternoon topics, activities, and objectives.

Table 3. Afternoon Training Content and Objectives

\begin{tabular}{|c|c|}
\hline $\begin{array}{r}\text { Topic/Discussion } \\
\end{array}$ & Objective \\
\hline $\begin{array}{l}\text { Five guiding values of TIC (activity) } \\
\text { - Small group discussion of what is already } \\
\text { happening in their programs around the five } \\
\text { values }\end{array}$ & $\begin{array}{l}\text { - Identify ways in which their programs are } \\
\text { already using TIC-strengths to build on } \\
\text { - Hear from other champions around what } \\
\text { they have in place }\end{array}$ \\
\hline $\begin{array}{l}\text { Steps for TIC culture change (lecture) } \\
\text { - Commitment by administration } \\
\text { - Universal screening, training/education, } \\
\text { hiring practices } \\
\text { - Review of policies and procedures } \\
\text { - Assessment/evaluation (Harris \& Fallot, } \\
\text { 2001) }\end{array}$ & $\begin{array}{l}\text { - Identify and understand what it takes to } \\
\text { create a trauma-informed organization }\end{array}$ \\
\hline $\begin{array}{l}\text { Organizational self-assessment (activity) } \\
\text { - Completed the "Trauma-Informed Care in } \\
\text { Youth Serving Settings: Organizational Self } \\
\text { Assessment" (Traumatic Stress Institute of } \\
\text { Klingberg Family Centers, n.d.) } \\
\text { - Discussion around what it was like to } \\
\text { complete the assessment }\end{array}$ & $\begin{array}{l}\text { - Identify and understand what it takes to } \\
\text { create a trauma-informed organization } \\
\text { - Identify areas of strength and improvement } \\
\text { in own program }\end{array}$ \\
\hline $\begin{array}{l}\text { Implementing TIC (lecture) } \\
\text { - Overview of SAMHSA (2014a) ten } \\
\text { implementation domains }\end{array}$ & $\begin{array}{l}\text { - Identify and understand what it takes to } \\
\text { create a trauma-informed organization } \\
\text { - Have a basic understanding of the ten } \\
\text { domains that will frame the rest of the } \\
\text { collaborative }\end{array}$ \\
\hline
\end{tabular}

Lastly, the trainers reviewed the schedule for the remainder of the collaborative and introduced the team's Samepage - a private web page that served as the main center of communication between consultations. The champions were informed that later that day, they would receive an e-mail invitation to the Samepage, their first homework assignment and a Survey Monkey link for the TIC attitudes and knowledge post-test to assess for 
changes from before the training. The trainers later reviewed the changes on the survey from pre- to post-test in order to inform future trainings.

\section{Samepage}

Due to both the length of the collaborative, and the majority of it taking place in an online format, the trainers wanted to have an online space for the team to interact between consultations. Thus, the trainers created a collaborative website on Samepage for the champion team to use throughout the training as depicted in Figure 1. Access to the website was provided by e-mail invitation after the initial training, so that only participants in the collaborative could view it. The Samepage was broken down into five sections: team files and resources, homework area, calendar, the "champion's resource corner," and a chat bar.

The trainers uploaded resources including documents and handouts, posted the PowerPoint slides after each consultation, and provided links to relevant TIC websites and videos in the team files and resources section. The homework area provided a space for champions to upload each assignment for others on the team to read, and provided information on assignment due dates and how to upload assignments. The calendar denoted each of the consultation options as well as the date and location of the final training.

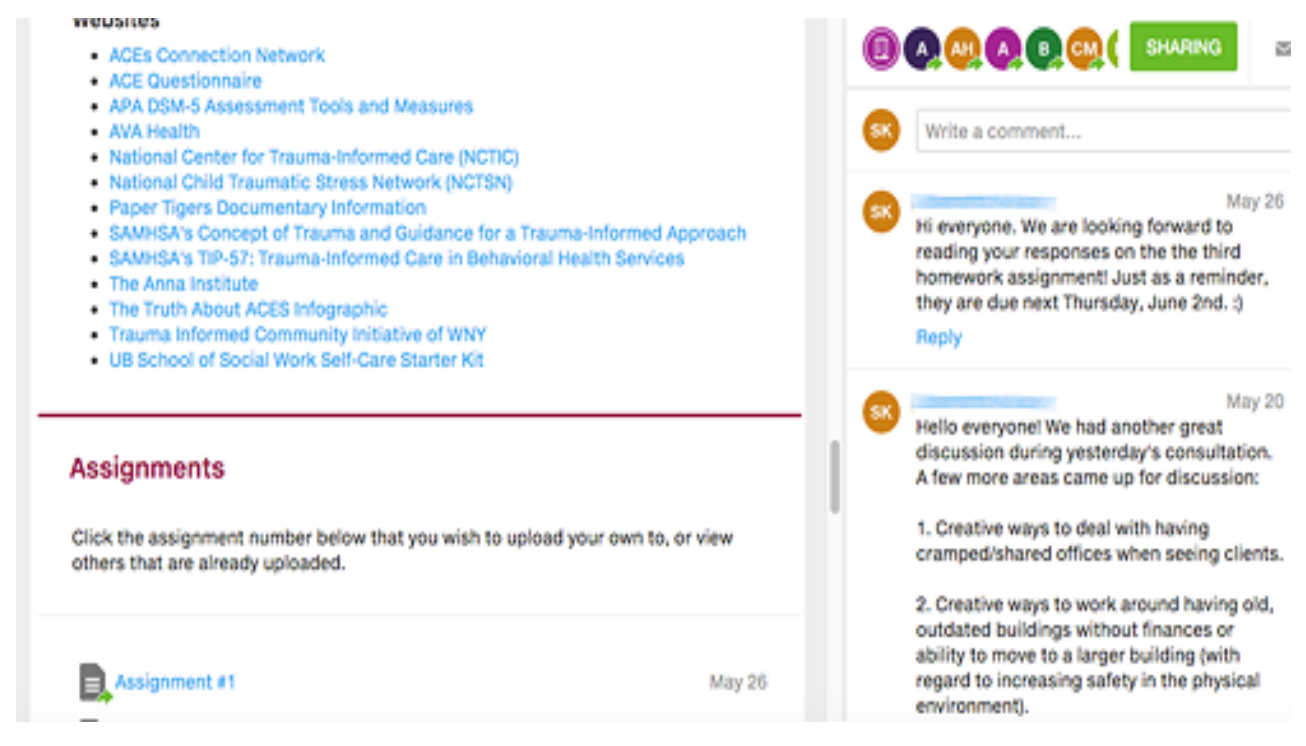

Figure 1.Samepage Example

The champions uploaded their own resources and asked for feedback on their ideas and plans around implementing TIC in the "Champion's Resource Corner." The "corner" provided a space where the trainers and team members could use Samepage's comment function to provide feedback on the uploaded material. Lastly, the "chat bar" provided a quick way for the team and trainers to communicate. Everyone with access to the page received an e-mailed each time a comment was left. The trainers often used the chat bar to 
ask the team questions and provide reminders for upcoming consultations and assignment due dates. The team was informed that the Samepage would be available to them even after the learning collaborative finished, so they would have a place with a collection of TIC resources and a means to reach out to other champions after the trainers were no longer involved.

\section{Monthly Consultations}

The third component of the learning collaborative involved consultations from months two through five. The champions were required to attend one of the two, 90-minute consultations each month. In order to keep the group size manageable, each offering had no more than 15 champions. The consultations were held through Blackboard Collaborate - an online collaborative learning platform that allows for audio, video, and text chat. The champions were provided with detailed instructions on how to download and run the software in advance. One of the trainers was also available by telephone to troubleshoot any technology problems.

General Format. In order to further operationalize what is involved in traumainformed organizational change, the content of each consultation was anchored around two of SAMHSA's (2014a) ten implementation domains. Governance and leadership and policy were covered in month two, physical environment and engagement and involvement in month three, cross-sector collaboration and screening, assessment, treatment services in month four, and training and workforce development and financing in month five. The final two, progress monitoring and quality assurance and evaluation, were included in the final training.

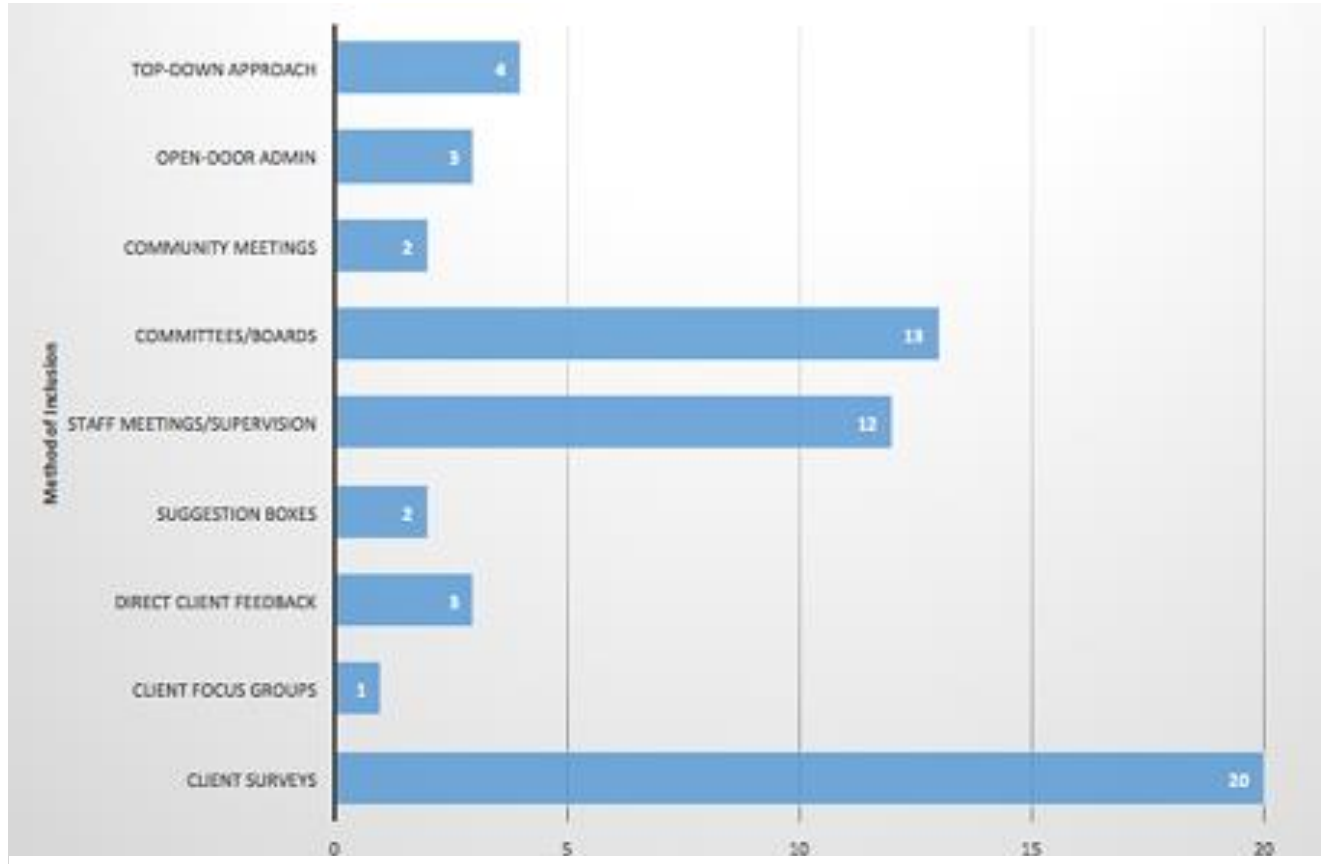

Figure 2 Example Homework Responses 
Although the content differed for each consultation, there were some structural components that remained the same. Each consultation started with a review of the day's agenda and a report of the team's homework responses. The trainers read the homework responses ahead of time so as to identify themes and create visual summaries for the homework report (see Figure 2). The report focused on the themes while highlighting some examples that were already in place. The champions were asked to listen and notice if anything resonated with them.

Each consultation also included an activity making use of scaling questions from the solution-focused model (DeJong \& Berg, 2013). The trainers compiled a list of "things to consider" for each domain - questions to operationalize the domains adapted from various sources (Harris \& Fallot, 2001; SAMHSA, 2014a, 2014b; Trauma Informed Oregon, 2015). The champions received the "things to consider" with space to write under each question ahead of time via e-mail and were asked to bring a printed copy to the session. During each consultation, champions were asked to choose one or two questions under each domain to look at more closely. The champions independently recorded their answers to the following three scaling questions:

On a scale from 1 to 10, with 10 representing your program's ideal implementation for that question and 1 being the complete opposite, where would you scale your agency right now? What is already happening that lets you know you are at that number (as opposed to a lower number)? And, what will be different if your agency were to move just one number higher on the scale?

Once the group reconvened, the champions shared one of the questions they thought about. The trainer then asked follow-up questions to help each champion come up with a next small step they could take in their role in order to help the program get one number higher on the scale.

Homework. Before each consultation, champions were required to complete short homework assignments around the two domains to be reviewed that month. Each domain had a total of two or three questions. The team was given approximately two weeks to complete each assignment before uploading their responses to the Samepage for others to view. The purpose of having the champions complete the assignments ahead of time was twofold: to have the champions begin to think about how each of the domains apply to their program already (strengths and areas for improvement), and to help the trainers focus discussion questions around where the team was regarding its current level of implementation and understanding for each domain. Table 4 below lists example homework questions. 
Table 4. Example Homework Questions

\begin{tabular}{|c|c|c|}
\hline HW & $\begin{array}{l}\text { Implementation } \\
\text { Domain }\end{array}$ & Question Example \\
\hline \multirow[t]{2}{*}{$\# 1$} & $\begin{array}{l}\text { Governance and } \\
\text { leadership }\end{array}$ & $\begin{array}{l}\text { Discuss thoughts you have regarding what you might say/do in } \\
\text { informing your leadership about TIC and your best hope for } \\
\text { your role within your agency. }\end{array}$ \\
\hline & Policy & $\begin{array}{l}\text { How do your agency's written policies and procedures already } \\
\text { include a focus on trauma-informed care, trauma-sensitive } \\
\text { care, and trauma-specific care? }\end{array}$ \\
\hline \multirow[t]{2}{*}{$\# 2$} & Physical environment & $\begin{array}{l}\text { Discuss how your organization considers the physical safety of } \\
\text { clients and staff. How does the physical environment promote } \\
\text { a calm and aesthetically comfortable setting? }\end{array}$ \\
\hline & $\begin{array}{l}\text { Engagement and } \\
\text { involvement }\end{array}$ & $\begin{array}{l}\text { Discuss thoughts you have around including client, peer, } \\
\text { family and staff voice and involvement in the planning, } \\
\text { implementation and evaluation of TIC in your agency. }\end{array}$ \\
\hline \multirow[t]{2}{*}{ \#3 } & $\begin{array}{l}\text { Cross sector } \\
\text { collaboration }\end{array}$ & $\begin{array}{l}\text { Is there a system of communication in place with your partner } \\
\text { agencies working with the individual receiving services for } \\
\text { making trauma-informed decisions? (SAMHSA, 2014a) }\end{array}$ \\
\hline & $\begin{array}{l}\text { Screening, assessment, } \\
\text { treatment services }\end{array}$ & $\begin{array}{l}\text { What screening/assessment tools are you using to screen for } \\
\text { adversity (ACE) and/or trauma (PTSD)? }\end{array}$ \\
\hline \multirow[t]{2}{*}{$\# 4$} & $\begin{array}{l}\text { Training and workforce } \\
\text { development }\end{array}$ & $\begin{array}{l}\text { What mechanisms and supports are in place to address the } \\
\text { emotional stress that can arise for staff/volunteers/peers when } \\
\text { working with individuals who have had traumatic experiences } \\
\text { (i.e., vicarious trauma)? }\end{array}$ \\
\hline & Financing & $\begin{array}{l}\text { Explore what is already in place or what will be in place to } \\
\text { support/finance a trauma-informed initiative in your agency. }\end{array}$ \\
\hline \multirow[t]{2}{*}{$\# 5$} & $\begin{array}{l}\text { Progress monitoring and } \\
\text { quality assurance }\end{array}$ & $\begin{array}{l}\text { How is your agency tracking the use of trauma-specific } \\
\text { screening, assessment, and treatment? }\end{array}$ \\
\hline & Evaluation & $\begin{array}{l}\text { How is your agency tracking the trauma-informed } \\
\text { initiative/approach? }\end{array}$ \\
\hline
\end{tabular}

Content. As stated previously, each of the consultations were framed in two of the ten implementation domains proposed by SAMHSA (2014a). The content and structure of the consultations were formulated collaboratively by two of the trainers based on the literature (British Columbia Center of Excellence for Women's Health, 2013; Harris \& Fallot, 2001; Lipsky \& Burk, 2009; Meichenbaum, n.d.; Pearlman \& McKay, 2008; SAMHSA, 2014a; SAMHSA, 2014b). The content was further adapted to fit the needs of the champions based on their homework responses. The consultations were largely discussion-based to give the champions opportunities to hear and learn from each other. Resources in the form of readings, handouts, websites, and tools were also provided where applicable. Table 5 showcases the content of each of the four consults and their objectives. 
Table 5. Consultation Content

\begin{tabular}{|c|c|c|}
\hline Consult & Topic/Discussion & Objective(s) \\
\hline $\begin{array}{c}\text { Governance \& } \\
\text { Leadership }\end{array}$ & $\begin{array}{l}\text { Creating culture change } \\
\text { - Review of the } 5 \text { guiding values and steps } \\
\text { for creating organizational change (Harris } \\
\text { \& Fallot, 2001) } \\
\text { - Resource - "Creating Cultures of Trauma- } \\
\text { Informed Care" (Fallot \& Harris, 2009) } \\
\text { Leadership and policy } \\
\text { - Introduction to the scaling questions } \\
\text { (activity) }\end{array}$ & $\begin{array}{l}\text { - Anchor around the nuances of } \\
\text { each of the five values } \\
\text { - Recognize the "big picture" of TIC } \\
\text { organizational change }\end{array}$ \\
\hline $\begin{array}{c}\text { \#2 } \\
\text { Physical } \\
\text { Environment }\end{array}$ & $\begin{array}{l}\text { Agency walkthroughs } \\
\text { - Walkthrough goals } \\
\text { - National Center on Substance Abuse and } \\
\text { Child Welfare[NCSACW] TIC Assessment } \\
\text { Project - physical space trauma triggers } \\
\text { (video) } \\
\text { - What are you noticing, or what has your } \\
\text { agency put in place around triggers in the } \\
\text { physical environment? (discussion) } \\
\text { Engagement: Agency readiness } \\
\text { - TIC organizational change interview } \\
\text { (video) } \\
\text { - What are you experiencing in your own } \\
\text { agency with regard to agency readiness for } \\
\text { creating a trauma-informed environment? } \\
\text { (discussion) } \\
\text { Role as a TIC champion } \\
\text { 10-minute solution-focused conversation } \\
\text { (activity; Fiske, 2010) }\end{array}$ & $\begin{array}{l}\text { - Identify agency's readiness for } \\
\text { becoming trauma-informed } \\
\text { - Begin to identify who in their } \\
\text { program might be a part of their } \\
\text { TIC workgroup/initiative } \\
\text { - Articulate their best hopes around } \\
\text { their role as a champion } \\
\text { - Formulate a next small step to take } \\
\text { in order to reach those best hopes }\end{array}$ \\
\hline $\begin{array}{c}\# 3 \\
\text { Cross Sector } \\
\text { Collaboration } \\
\\
\text { Screening, } \\
\text { Assessment, } \\
\text { Treatment } \\
\text { Services }\end{array}$ & $\begin{array}{l}\text { Collaborative partners } \\
\text { - How might knowing where collaborative } \\
\text { partners are in their understanding of } \\
\text { trauma-informed, trauma-sensitive and } \\
\text { trauma-specific services impact your } \\
\text { own/your staff's work with partners? } \\
\text { (discussion) } \\
\text { Screening/assessment/treatment } \\
\text { - Resources - TIP-57 pg 91-110 (SAMHSA, } \\
\text { 2014b); "Child and Adolescent Trauma } \\
\text { Measures: A Review" (Strand, Pasquale \& } \\
\text { Sarmiento, 2003); DSM-5 assessment tools } \\
\text { and measures (APA, 2017) } \\
\text { - If someone is referred to your agency, how } \\
\text { do you know if they've already been }\end{array}$ & $\begin{array}{l}\text { - Understand the implications of } \\
\text { working with partners who are not } \\
\text { trauma-informed, trauma-sensitive } \\
\text { and/or trauma-specific } \\
\text { - Increase awareness of the } \\
\text { importance of collaborating with } \\
\text { partners around TIC } \\
\text { - Identify resources for choosing } \\
\text { appropriate screening/assessment } \\
\text { tools } \\
\text { - Understand the importance of } \\
\text { knowing what trauma } \\
\text { screening/assessment tools have } \\
\text { been used by referral sources }\end{array}$ \\
\hline
\end{tabular}




\begin{tabular}{|c|c|c|}
\hline Consult & Topic/Discussion & Objective(s) \\
\hline & $\begin{array}{l}\text { screened/assessed for trauma? What tools } \\
\text { have been used? (discussion) } \\
\text { - Is there anyone in your agency you would } \\
\text { see as a "trauma expert"? } \\
\text { Guest speaker } \\
\text { - TIC champion from a local agency came to } \\
\text { talk about their process in becoming trauma- } \\
\text { informed, largely framed in the two domains } \\
\text { for this consult } \\
\text { - Time for questions included }\end{array}$ & $\begin{array}{l}\text { Identify who, if anyone, in their } \\
\text { agency is knowledgeable about } \\
\text { trauma through education/training } \\
\text { that could be a point person for } \\
\text { decisions around screening, } \\
\text { assessment, treatment and/or } \\
\text { referrals } \\
\text { - Hear from a TIC champion from } \\
\text { an agency further in the process of } \\
\text { becoming trauma-informed }\end{array}$ \\
\hline $\begin{array}{c}\text { \#4 } \\
\text { Training \& } \\
\text { Workforce } \\
\text { Development }\end{array}$ & $\begin{array}{l}\text { Staff Training (provided during HW report) } \\
\text { - } \quad \text { Resource - Treatment Improvement } \\
\text { Protocol [TIP]-57 pg179-183; appendix B } \\
\text { (SAMHSA, 2014b) } \\
\text { Supervision (provided during HW report) } \\
\text { - Resource - TIP-57 pg 93, 191, 195, 197, } \\
\text { 205 (SAMHSA, 2014b) } \\
\text { Agency supports } \\
\text { - How are you/co-workers/staff managing } \\
\text { around the loss of clients? What is in place } \\
\text { for residents/clients? For staff? (discussion) } \\
\text { Impact of trauma on staff } \\
\text { - Secondary traumatic stress, vicarious } \\
\text { trauma, compassion fatigue, burnout } \\
\text { (overview) } \\
\text { - What do you notice about } \\
\text { individual/organizational risk factors? } \\
\text { (discussion) } \\
\text { - What do you notice about } \\
\text { individual/organizational protective } \\
\text { factors? (discussion) } \\
\text { - Awareness-Balance-Connection (ABCs) } \\
\text { - Relf-care assessment (activity) } \\
\text { Scale [ProQoL] (Stamm, 2010); University } \\
\text { at Buffalo School of Social Work self-care } \\
\text { starter kit (Butler \& McClain-Meeder, } \\
\text { 2015). }\end{array}$ & $\begin{array}{l}\text { - Identify resources to address } \\
\text { champion-stated areas of } \\
\text { improvement around providing } \\
\text { TIC staff training and supervision } \\
\text { - Identify how they and others in } \\
\text { their programs are managing } \\
\text { (strengths) in face of the reality of } \\
\text { losing clients } \\
\text { - Recognize the importance of } \\
\text { agency supports for staff } \\
\text { - Understand the ways trauma can } \\
\text { impact staff } \\
\text { - Identify what might put staff at a } \\
\text { higher risk for being negatively } \\
\text { impacted by trauma } \\
\text { - Identify what may decrease the } \\
\text { risk of staff being negatively } \\
\text { impacted by trauma } \\
\text { - Increase awareness of their own } \\
\text { self-care } \\
\text { - Understand key components of } \\
\text { effective coping } \\
\text { - Identify further resources for } \\
\text { assessing and promoting self-care }\end{array}$ \\
\hline
\end{tabular}

Evaluations. Each consultation had its own evaluation for the purpose of informing future consultations. The champions who attended any given consultation received a link to an online Survey Monkey to provide feedback. Although they were encouraged to provide their feedback in order to help the trainers make adjustments to future consultations, 
their participation was completely anonymous and voluntary. Using a Likert scale, the champions completed the evaluation, which asked how helpful the components of the consultation were, how much the consultation helped their understanding of the content covered, and how much of the content they thought they would use in the planning and implementation of a trauma-informed approach. The evaluations also had two open-ended questions that asked the champions to indicate the most helpful part of the consultation and how the consultation could have been more helpful. Evaluations were reviewed while planning for subsequent consultations and small adjustments were made to technology, facilitation style, and activities.

\section{Final Training}

The learning collaborative ended with a four-hour, in-person training during month six. The PowerPoint slides were posted to the Samepage so that the champions could print the slides if they wished. The trainers spent time checking in with the team by asking the champions to consider what they noticed different about themselves compared to the initial training. Each champion was encouraged to share their thoughts about the training.

The first half of the training focused on resilience and posttraumatic growth. The champions were divided into groups of three and were given a small slip of paper with questions about resilience. Additional questions were provided after short periods of time for the groups to continue their discussions. After the group reconvened and talked about what came up for each of them, one of the trainers provided a brief overview of resilience and posttraumatic growth. The team then took a short break and reconvened to talk about their experiences being in a six-month learning collaborative and to have a deliberate conversation about the parallel process that occurred over the six months. In order to anchor a short discussion around the progress monitoring and quality assurance and evaluation domains, the team re-visited the same agency self-assessment they completed in the initial training. Table 6 below depicts the content covered in the first half of the training and its objective.

Table 6. Morning Content and Objectives

\begin{tabular}{|c|c|}
\hline Topic/Discussion & Objective(s) \\
\hline $\begin{array}{l}\text { Tuning into the Work (small group activity) } \\
\text { - What challenges have you witnessed your } \\
\text { clients/other staff/organization overcoming in your } \\
\text { work with them? } \\
\text { - How have you been positively impacted by } \\
\text { witnessing this resilience? } \\
\text { - How has your perception of yourself been } \\
\text { changed by witnessing this resilience? Your } \\
\text { perception of your work? } \\
\text { - How has your world view been changed by } \\
\text { witnessing this resilience? }\end{array}$ & $\begin{array}{l}\text { - Recognize the positive impacts the work has on } \\
\text { them }\end{array}$ \\
\hline
\end{tabular}




\begin{tabular}{|c|c|}
\hline Topic/Discussion & Objective(s) \\
\hline $\begin{array}{l}\text { Resilience/Posttraumatic Growth (lecture) } \\
\text { - Brief review of vicarious trauma \& coping } \\
\text { - Transformation of vicarious trauma } \\
\text { - Defining resilience } \\
\text { - Interpersonal factors of resilience } \\
\text { - Vicarious resilience } \\
\text { - Posttraumatic growth }\end{array}$ & $\begin{array}{l}\text { - Have a basic understanding of resilience, } \\
\text { vicarious resilience and posttraumatic growth } \\
\text { - Identify ways to build resilience into the } \\
\text { workplace }\end{array}$ \\
\hline $\begin{array}{l}\text { Parallel process (overview, brief discussion) } \\
\text { - What was it like being in a 6-month learning } \\
\text { collaborative? } \\
\text { - Deliberate look at everything involved in the } \\
\text { collaborative and how each component promoted } \\
\text { a parallel process - content and the means to bring } \\
\text { the content to others }\end{array}$ & $\begin{array}{l}\text { - Identify skills, discussion points, activities and } \\
\text { other means of teaching and coaching that the } \\
\text { trainers used during the learning collaborative } \\
\text { - Consider which means of teaching and } \\
\text { coaching make sense in light of their role as a } \\
\text { champion and where their agency is at }\end{array}$ \\
\hline $\begin{array}{l}\text { Agency assessment (activity, brief discussion) } \\
\text { - Filled out the same agency assessment they } \\
\text { completed during the initial training and then } \\
\text { compared }\end{array}$ & $\begin{array}{l}\text { - Further understand the progress monitoring and } \\
\text { quality assurance, and evaluation } \\
\text { implementation domains } \\
\text { - Recognize any changes that have occurred over } \\
\text { the course of the collaborative }\end{array}$ \\
\hline
\end{tabular}

The remainder of the training was spent focusing on TIC action planning through activities and discussion. First, the champions were given three circles divided into ten sections - each section labeled with one of the SAMHSA (2014a) ten implementation domains. In an activity adapted from Integrative Nutrition, Inc. (2006), the champions were asked to place a dot on the line of each domain to visually display where they saw themselves - the center of the circle represented not being competent, while the periphery represented their ideal competence. They were then asked to consider their own level of competence on the first handout, their agency's level of competence on the second handout, and their agency's level of implementation on the third handout for each domain. Once finished with the plotting, the champions were instructed to connect the dots on each circle to have an overall display of their competence, their agency's competence, and their agency's level of implementation.

The back of each circle handout had a chart with each of the implementation domains listed in one column and space to explain the capacities and strengths associated with each. The champions were asked to pick just two domains to fill in on each chart based on their plotting on the front of the handout. Once they finished working on the circles and their associated charts, the team was divided into pairs and given a handout with a ten-minute solution-focused conversation adapted from Fiske (2010). Using the framework provided, the champions had a conversation around implementing one of the domains they focused on in the previous activity into their work. Each champion had the opportunity to be in the role of the person asking questions and the one answering questions. The solution-focused conversation framework helped each of the champions identify a next small step they could take in order to reach their ideal implementation for that domain. 
The trainers then handed out one additional chart titled, "Trauma-Informed Care Implementation Action Plan." The chart listed all ten domains in one column, had a column to rate the agency on a scale from one to ten, a column for the champion's next step, and a final column for the agency's next step. The trainers explained that the chart would be filled out based on all of the action-planning activities and discussions they had up until that point, and could thus be used to create an action plan with others in their agency.

The training concluded by having a short discussion around how the team would stay in contact after that day. The trainers then called each champion up one by one to receive their certificate of completion for the learning collaborative. The champions were informed that there would be additional resources posted to their Samepage based on their conversations that day and that they would also be receiving one last online evaluation. The trainers thanked the champions for their participation in the learning collaborative and encouraged them to stay connected to each other.

Evaluation. The evaluation for the closing training was e-mailed later that day to those who attended. Similar to previous evaluations, the final evaluation asked the respondents what was helpful, how well the training met their needs, how confident they felt in their role as a TIC champion and if they felt they had the tools to create a TIC implementation plan. Additionally, there were three free-text questions that asked about what was most helpful about the training, what could have made the training more helpful, and a space for any other comments or feedback about the collaborative in general.

\section{Trainer Experiences}

In addition to online evaluations for each of the consultations, the trainers took note of their experiences facilitating the learning collaborative and debriefed together after each training or consultation. This activity allowed the trainers to recognize a number of strengths and challenges associated with the six-month learning collaborative.

\section{Strengths}

The champions often verbally reported how they appreciated the learning collaborative occurring over a six-month period. TIC was on the forefront of their minds because they had to be accountable to the trainers and to the rest of the team each month through submitting homework assignments and attending the consultations. Otherwise, many stated TIC would have likely been "lost in the shuffle" or consistently moved to the bottom of their "to-do" lists. The majority of the 30 team members were engaged and participated in all of the learning collaborative components. Further, the homework assignments and consultations facilitated the champions' thinking about TIC, conversations with coworkers around TIC, and how to apply the guiding values and implementation domains within their own programs more consistently than if they had only attended a regular training. Much like Buono and Subbiah (2014)'s operationalization of the role of an internal change agent as regularly monitoring and overseeing the organizational change process, and Harris and Fallot's (2001) recommendation for the identification of champions in order to keep the TIC initiative active and in the forefront of all agency 
functioning, the learning collaborative helped model this expectation of being a TIC champion.

Creating a sense of being a "champion team" was another apparent strength of the learning collaborative model. By the second or third consultation, the champions often consulted with fellow team members instead of asking the trainers facilitating the consultations. The champions also expressed that hearing from others on the team was helpful, not only because they were reassured by others being "in the same boat," but also because they were able to think of new ideas and next steps by hearing what others were doing. Such observations are in line with previous research findings that show some effectiveness of mutual aid group processes such as shared experience and building on others' expertise/views increasing group member confidence and learning (Finch \& Feigelman, 2008; Shulman, 2008; Steinberg, 2010). One of the champions suggested creating a contact directory of those who would be willing to stay in touch, and the others readily agreed. The champions also discussed the possibility of continuing to have their own "consultation calls" without the trainers in order to keep the process going. The team continued the process of mutual aid by deciding on their own that they wanted to stay connected even after the collaborative ended in order to keep helping and supporting each other (Steinberg, 2010).

Lastly, the trainers noticed the champion team had grown in their ability to understand and think critically about TIC. By the final training in month six, the champions were using the five values in their language more frequently and were able to articulate barriers and possible solutions to implementing TIC within the ten domains. Many of the champions reported a difference in themselves in month six compared to the first month of the collaborative-including feeling more confident in their understanding and ability to bring aspects of TIC back to their programs. These observations resonate with findings and suggestions in the literature that longitudinal, multifaceted training programs may be more effective than single-day workshops in facilitating long-lasting changes and confidence in implementing TIC (Hall et al., 2016; Hoge et al., 2007; Pearce et al., 2012).

\section{Challenges}

Technology was the biggest challenge throughout the collaborative. Despite one of the trainers making herself available to troubleshoot with the champions who were having difficulty, a portion of the team went through all of the consultations without having audio capabilities. Even though an external headset was recommended for participation, not all of the champions were able to get one, and their computers were not equipped with microphones. These champions had to participate by typing their answers, comments, and questions into the "chat box." One of the two trainers facilitating the consultations read these champions' comments out loud and addressed what was said to include them as much as possible, but the flow of the consultations and ability to have an interactive group discussions were impacted by a portion of the team not having audio capacity. Additionally, background noise from the room where the trainers were facilitating the discussions resulted in some champions having difficulty hearing the trainers. The trainers also purchased headsets after the first consultation, which significantly improved the audio. Unfortunately, the Blackboard Collaborate technology occasionally lagged, skipped 
portions of the training, and even disconnected for some of the champions, which caused difficulties in the champions' ability to participate. Isolation and decreased interactions caused by technology challenges may be a factor that leads to dissatisfaction with the learning collaborative and/or inhibited learning (Jang \& Kim, 2014; Koutsoupidou, 2014). Investigating other online learning platforms such as WebEx, where participants can participate via the telephone, might be worthwhile.

Another challenge was the lack of opportunity to make up any pieces of the collaborative that were missed. The dates of the consultations and closing training were selected by the trainers and given to the champions prior to the initial training. However, some champions missed one or two consultations due to technology, a work-related crisis, or being sick. One of the trainers made herself available to touch base over the telephone for 15-20 minutes for champions who were unable to attend a consultation and wanted to get caught up; however, these champions still missed the experience of being a part of the consultation with their peers. Giving absent champions access to recordings of the sessions could provide some of the experience of being in the consultation that they missed. As Blackboard Collaborate does have the ability to record, it may be worth recording the sessions in a future learning collaborative for those who are absent to watch in addition to following up with one of the trainers.

One last challenge was the small number of champions who completed the evaluations after each consultation and the closing training. Though the evaluations were voluntary, the champions were encouraged each time to provide their feedback so that the trainers could modify future consultations to better meet their needs. Additionally, those who did provide feedback did not always write an answer to the free text question of what might have made the consultation more helpful for them. The trainers made some adjustments based on the feedback that was given, especially around any technology challenges. However, it was difficult to know how the learning collaborative was being received by the team as a whole due to the low response rate.

\section{Implications}

Based on verbal reports from participants and the experiences of the trainers facilitating the learning collaborative, the model appears to have initial evidence of being an effective means of training TIC champions. However, as the described collaborative was not a research study, further quantitative research is required in order to truly evaluate the effectiveness of the learning collaborative. Evaluation tools other than those collected for the trainers' use could be implemented to assess understanding and implementation steps taken throughout and the collaborative. Follow-up evaluations after the completion of the learning collaborative would also be important in assessing long-term understanding and implementation, as the primary purpose of training champions is to build sustainability for TIC organizational change. Additionally, the participants in the learning collaborative were from agencies working with adolescents who have substance use diagnoses. Facilitating the learning collaborative with different types of service providers while collecting data would increase the generalizability of the findings. Future studies comparing the learning collaborative model to other means of TIC training, such as single workshops, would also 
add to the literature by determining whether the collaborative is more effective than the comparison training modality.

As more organizations and systems of care make the shift to becoming traumainformed, there will be an increasing need for effective training modalities. Although further research is necessary to provide a better understanding of the learning collaborative model's effectiveness, the collaborative is an example of how individuals from 30 different agencies can be trained and developed into TIC champions, who are then in a position to train their co-workers and other staff, understand what is required to become a traumainformed agency, and help ultimately support their agency in the implementation of TIC.

\section{References}

American Psychiatric Association [APA]. (2013). Diagnostic and statistics manual of mental disorders $\left(5^{\text {th }}\right.$ ed.). Arlington, VA: American Psychiatric Press.

APA. (2017). Disorder-specific severity measures. Retrieved from https://www.psychiatry.org/psychiatrists/practice/dsm/educationalresources/assessment-measures

American Psychological Association. (2016). The road to resilience. Retrieved from http://www.apa.org/helpcenter/road-resilience.aspx

Bassuk, E. L., Unick, G. J., Paquette, K., \& Richard, M. K. (2017). Developing an instrument to measure organizational trauma-informed care in human services: The TICOMETER. Psychology of Violence, 7(1), 150-157. doi: http://dx.doi.org/10.1037/vio0000030

Bloom, S. L. (2013). Creating sanctuary: Toward the evolution of sane societies. Abingdon, UK: Routledge.

British Columbia Centre of Excellence for Women's Health. (2013). Trauma-informed practice guide. Retrieved from http://nccewh.bc.ca/wpcontent/uploads/2012/05/2013_TIP-Guide.pdf

Buchanan, D., Fitzgeral, L., Ketley, D., Gollop, R., Jones, J. L., Lamont, S. S., . . Whitby, E. (2005). No going back: A review of the literature on sustaining organizational change. International Journal of Management Reviews, 7(3), 189-205.

Buono, A. F., \& Subbiah, K. (2014). Internal consultants as change agents: Roles, responsibilities and organizational change capacity. Organizational Development Journal, 32(2), 35-53.

Butler, L. D., \& McClain-Meeder, K. (2015). Self-care starter kit. Retrieved from http://socialwork.buffalo.edu/resources/self-care-starter-kit.html

Calvo, M., Ukeje, C., Abraham, R., \& Libman, K. (2016). Trauma-informed \& resilient communities: A primer for public health practitioners. Retrieved from http://www.advancingpreventionproject.org/wp-content/uploads/2016/06/TraumaPrimer-Final.pdf

DeJong, P., \& Berg, I. K. (Eds.). (2013). Interviewing for solutions ( $4^{\text {th }}$ ed.). Belmont: 
Thomson Brooks/Cole.

Fallot, R. D., \& Harris, M. (2009). Creating cultures of trauma-informed care (CCTIC): A self-assessment and planning protocol. Retrieved from https://www.healthcare.uiowa.edu/icmh/documents/CCTICSelfAssessmentandPlanningProtocol0709.pdf

Felitti, V. J., Anda, R. F., Nordenberg, D., Williamson, D. F., Spitz, A. M., Edwards, V., . . Marks, J. S. (1998). Relationship of childhood abuse and household dysfunction to many of the leading causes of death in adults: The adverse childhood experiences (ACE) study. American Journal of Preventative Medicine, 14(4), 245258. doi: https://doi.org/10.1016/S0749-3797(98)00017-8

Finch, J. B., \& Feigelman, B. (2008). The power of mutual aid in the educational process: A seminar for new field instructors of trainees. The Clinical Supervisor, 27(2), 191214. doi: http://dx.doi.org/10.1080/07325220802487931

Fiske, H. (2010). A 10-minute solution-focused interview training exercise. In T. S. Nelson (Ed.), Doing something different: Solution-focused brief therapy practices (pp.183-184). New York: Routledge.

Greenwald, R. (2014). Child trauma handbook: A guide for helping trauma-exposed children. New York: Routledge.

Hall, A., McKenna, B., Dearie, V., Maguire, T., Charleston, R., \& Furness, T. (2016). Educating emergency department nurses about trauma informed care for people presenting with mental health crisis: A pilot study. BMC Nursing, 15(21) [online]. doi: https://doi.org/10.1186/s12912-016-0141-y

Harris, M., \& Fallot, R. D. (Eds.). (2001). Using trauma theory to design service Systems. New Directions for Mental Health Services. San Francisco: Jossey-Bass.

Hoge, M. A., Morris, J. A., Daniels, A. S., Stuart, G. W., Huey, L. Y., \& Adams, N. (2007). An action plan for behavioral health workforce development: A framework for discussion. Rockville, MD: Substance Abuse and Mental Health Services Administration.

Horner, G. (2015). Childhood trauma exposure and toxic stress: What the PNP needs to know. Journal of Pediatric Health Care, 29(2), 191-198. doi: http://dx.doi.org/10.1016/j.pedhc.2014.09.006

Integrative Nutrition, Inc. (2006). The integrative nutrition journal: Your guide to a happier, healthier life. New York: Integrative Nutrition, Inc.

Jang, H. W., \& Kim, K-J. (2014). Use of online clinical videos for clinical skills training for medical students: Benefits and challenges. BMC Medical Education, 14(56), 1-6.

Jennings, A. (1994). On being invisible in the mental health system. Journal of Mental Health Administration, 21(4), 374-387. doi: https://doi.org/10.1007/BF02521356 
Jennings, A. (2009). Models for developing trauma-informed behavioral health systems and trauma-specific services: 2008 update. Alexandria, VA: National Center for Trauma-Informed Care.

Kilpatrick, D. G., Resnick, H. S., Milanak, M. E., Miller, M. W., Keyes, K. M., \& Friedman, M. J. (2013). National estimates of exposure to traumatic events and PTSD prevalence using DSM-IV and DSM-5 criteria. Journal of Traumatic Stress, 26, 537-547. doi: https://doi.org/10.1002/jts.21848

Koutsoupidou, T. (2014). Online distance learning and music training: benefits, drawbacks and challenges. Open Learning, 29(3), 243-255. doi: http://dx.doi.org/10.1080/02680513.2015.1011112

Lipsky, L. V. D., \& Burk, C. (2009). Trauma stewardship: An everyday guide to caring for self while caring for others. San Francisco, CA: Berrett-Koehler Publishers, Inc.

Meichenbaum, D. (n.d.). Self-care for trauma psychotherapists and caregivers: Individual, social and organizational interventions. Retrieved from https://www.melissainstitute.org/documents/Meichenbaum SelfCare 11thconf.pdf

Muskett, C. (2014). Trauma-informed care in inpatient mental health settings: A review of the literature. International Journal of Mental Health Nursing, 23, 51-59. doi: https://doi.org/10.1111/inm.12012

Pearce, J., Mann, M. K., Jones, C., van Buschbach, S., Olff, M., \& Bisson, J. I. (2012). The most effective way of delivering a train-the-trainers program: A systematic review. Journal of Continuing Education in the Health Professions, 32(3), 215-266. doi: https://doi.org/10.1002/chp.21148

Pearlman, L. A., McKay, L. (2008). Understanding \& addressing vicarious trauma: Online training module four. Retrieved from http://www.headingtoninstitute.org/files/vtmoduletemplate2_ready_v2_85791.pdf

Roberts, Y. H., Huang, C. Y., Crusto, C. A., \& Kaufman, J. S. (2014). Health, emergency department use, and early identification of young children exposed to trauma. Journal of Emergency Medicine, 46(5), 719-724. doi: http://dx.doi.org/10.1016/j.jemermed.2013.11.086

Schein, E. H. (2010). Organizational culture and leadership (Vol. 2). Hoboken, NJ: John Wiley \& Sons.

Stamm, B. H. (2010). The concise ProQoL manual. Retrieved from https://nbpsa.org/images/PRP/ProQOL_Concise_2ndEd_12-2010.pdf

Steiker, L. H. (2015). Trauma-informed care and addiction recovery: An interview with Nancy J. Smyth, PhD, LCSW. Journal of Social Work Practice in the Addictions, 15, 134-142. doi: https://doi.org/10.1080/1533256X.2015.996509

Steinberg, D. M. (2010). Mutual aid: A contribution to best-practice social work. Social Work with Groups, 33(1), 53-68. doi: https://doi.org/10.1080/01609510903316389 
Substance Abuse and Mental Health Services Administration [SAMHSA]. (2014a). Concept of Trauma and Guidance for a Trauma-Informed Approach. Retrieved from http://store.samhsa.gov/shin/content/SMA14-4884/SMA14-4884.pdf

SAMHSA. (2014b). Trauma-informed care in behavioral health services: Treatment improvement protocol (TIP) series 57. Rockville, MD: Author.

Schultz, C. (2014). Learning is change: Creating an environment for sustainable organizational change in continuing and higher education. Canadian Journal of University Continuing Education, 40(1), 1-26.

Shulman, L. (2008). The skills of helping individuals, families, groups and communities. (6th ed.). Belmont, CA: Brooks/Cole.

Strand, V. C., Pasquale, L. E., \& Sarmiento, T. L. (2003). Child and adolescent trauma measures: A review. Retrieved from https://ncwwi.org/files/Evidence Based and Trauma-Informed Practice/Child-andAdolescent-Trauma-Measures_A-Review-with-Measures.pdf

Tedeschi, R. G., \& Calhoun, L. G. (2004). Posttraumatic growth: Conceptual foundations and empirical evidence. Psychological Inquiry, 15(1), 1-18. doi:

https://doi.org/10.1207/s15327965pli1501_01

Trauma Informed Oregon. (2015). Standards of practice for trauma-informed care. Retrieved from http://traumainformedoregon.org/wpcontent/uploads/2016/07/Guidelines-Crosswalk-Standards-of-Care-for-TraumaInformed-Care.pdf

Traumatic Stress Institute of Klingberg Family Centers. (n.d.). Trauma-informed care in youth serving settings: Organizational self assessment. Retrieved from http://traumaticstressinstitute.org/wp-content/uploads/2010/06/Trauma-InformedCare-Org-Self-Assessment-Final.pdf

Wolf, M. R., Green, S. A., Nochajski, T. H., Mendel, W. E., \& Kusmaul, N. S. (2014). 'We are civil servants': The status of trauma-informed care in the community. Journal of Social Service Research, 40, 111-120. doi: https://doi.org/10.1080/01488376.2013.845131

\section{Author note:}

Address correspondence to: Susan A. Green, School of Social Work, University at Buffalo, 664 Baldy Hall, Buffalo, NY 14260, 716-645-1249, sagreen@buffalo.edu 